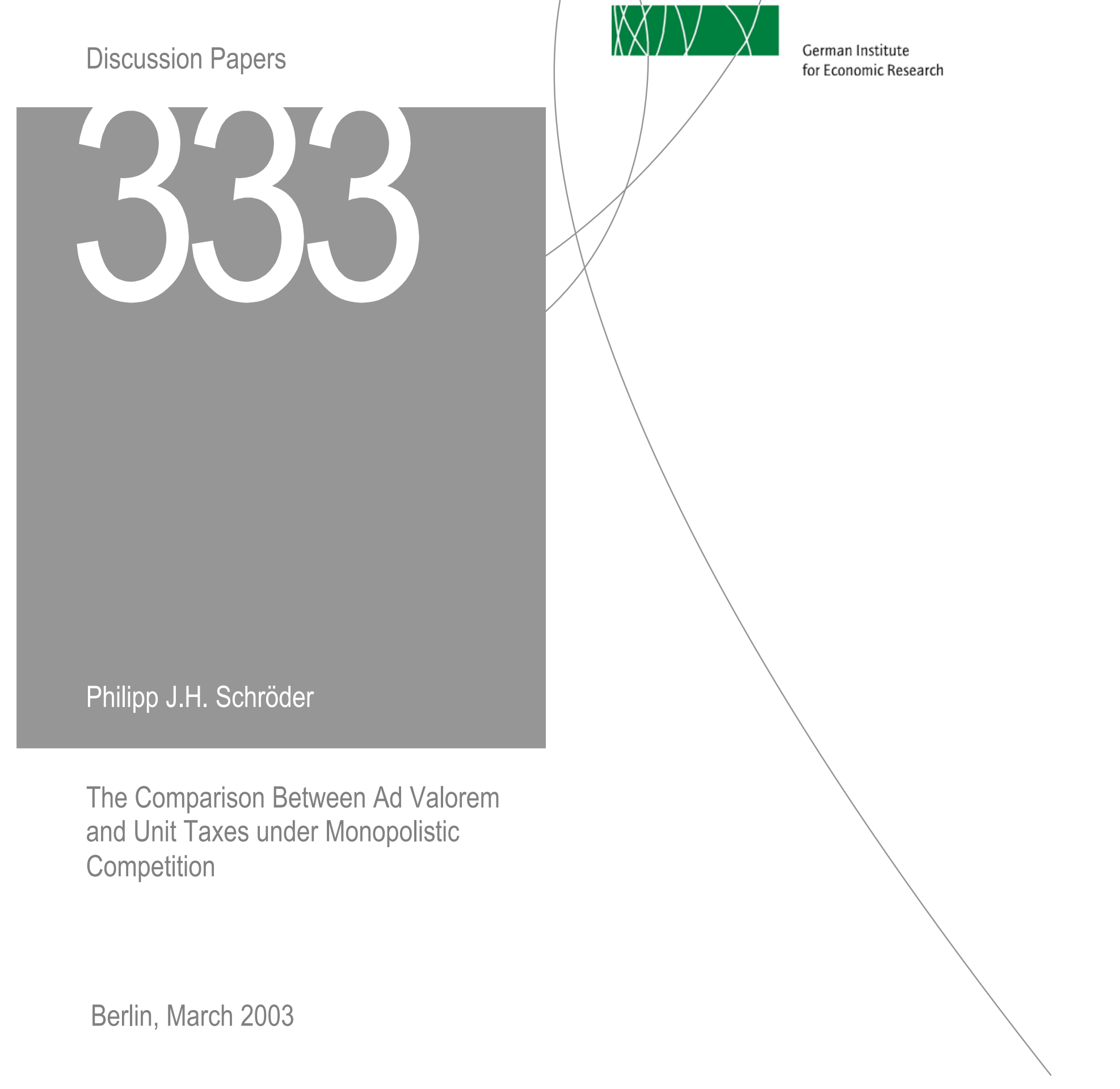


Opinions expressed in this paper are those of the author and do not necessarily reflect views of the Institute.

\section{DIW Berlin}

\section{German Institute}

for Economic Research

Königin-Luise-Str. 5

14195 Berlin,

Germany

Phone +49-30-897 89-0

Fax +49-30-897 89-200

www.diw.de

ISSN 1619-4535 


\title{
The Comparison Between Ad Valorem and Unit Taxes under Monopolistic Competition
}

\author{
Philipp J.H. Schröder*
}

February 2003

\begin{abstract}
This paper shows that the welfare dominance of ad valorem over unit taxes under imperfect competition, extends to the Dixit-Stiglitz framework with differentiated products, entry and love of variety. This contrasts against findings by Anderson et al. (J Public Econ, 2001) made in a similar framework, but under Bertrand competition.

Key Words: Unit tax; Specific tax; Ad valorem tax; Welfare

JEL: D43; H21; H22; L13
\end{abstract}

\section{Introduction}

Since the writings of Cournot and Wicksell it is well know that the equivalence of unit (specific) and ad valorem taxes under perfect competition ceases to exist for settings of monopoly. With the works of Suits and Musgrave (1953) and Delipalla and Keen (1992), a consensus that ad valorem taxes welfare dominate equal yield unit taxes for a wide range of imperfect competitive settings has been obtained. ${ }^{1}$

This paper augments the literature by comparing the two tax instruments under monopolistic competition, i.e. a Dixit and Stiglitz (1977) type setting that includes the desirability of variety, differentiated products, economies

*DIW Berlin, German Institute for Economic Research, Königin-Luise-Straße 5, 14195 Berlin, Germany, Tel.: +49 30 89789-692 (Fax: -108), E-mail: pschroeder@diw.de. Comments and suggestions from Anthony Atkinson, Jürgen Bitzer, Rainald Borck and David Collie are gratefully acknowledged.

${ }^{1}$ See also Skeath and Trandel (1994), Myles (1996) and Hamilton (1999). For the policy relevance of the two tax instruments and a review of the literature see Keen (1998). 
of scale and market entry. ${ }^{2}$ We find that the welfare superiority of an ad valorem tax to an equal yield unit tax does indeed extend to this case.

The monopolistic competition model of Dixit and Stiglitz (1977), though widely used in industrial economics and international economics, has found relatively little application in public finance. ${ }^{3}$ Yet the approach has a number of interesting features. First, it provides a consistent framework where consumers value variety and where there is entry and product differentiation. Second, it is inherently a general equilibrium approach, such that e.g. the full consequences of redistributing taxes can be studied. Third, since it takes its starting point in the consumer utility function, there is a natural measure of welfare.

The finding of this paper is particularly important in relation to recent contributions made by Anderson et al. (2001a and 2001b). They have extended the literature of taxes under imperfect competition to settings with Bertrand competition and differentiated products. Anderson et al. (2001b) establish, inter alia, that the welfare dominance of ad valorem taxes can be challenged by a unit tax once there is free entry and love of variety. The reason is that the superior ability of the ad valorem tax to extract firm profits reduces entry incentives and hence the number of variants and welfare. On the other hand since a unit tax displays a higher rate of over-shift, firm profits are higher and so are entry and welfare. Since the present model features the central characteristics of Anderson et al. (2001b), i.e. differentiated products, market entry and love of variety, but not the same mode of competition (Cournot-Nash), it constitutes a relevant comparison. In particular, Anderson et al. (2001b) raise the question whether it is the mode of competition or the introduction of product differentiation (love of variety) that produces the result. The present paper indicates that the mode of competition is decisive.

The following section introduces the model. Section 3 derives the welfare ranking between the two tax instruments. Section 4 concludes.

\footnotetext{
${ }^{2}$ A comprehensive treatment of taxation under monopolistic competition is due to Stern (1987), who presents results, based on a conjectural-variations model of partial equilibrium free entry Cournot-oligopoly, thus with homogeneous goods and without love of variety.

${ }^{3}$ An important exception are Atkinson and Stiglitz (1980, ch.7). Nevertheless, out of the 707 citations of Dixit and Stiglitz (1977) that are recorded in the Social Sciences Citation Index only 8 are in the Journal of Public Economics (non of them examining the two tax instruments). In comparison, the Journal of Industrial Economics and the Journal of International Economics account for 22 citations each.
} 


\section{The Model}

Consider a sector (industry) where market conditions are characterised by monopolistic competition. ${ }^{4}$ The industry has a large number of potential variants (firms), $N$, which enter symmetrically into demand. The number of variants actually produced is $n<N$ and is assumed to be large. The output of firm $i$ is denoted by $x_{i}$. All firms have the same cost structure $l_{i}\left(x_{i}\right)=\left(f+\beta x_{i}\right)$ where $l_{i}$ is labour - the only factor of production -, where $f$ is the fixed costs of production and $\beta$ are marginal costs. The economy wide wage rate is $w$. The consumer price is given by the inverse demand function $P\left(x_{i}\right)$. Under an ad valorem tax $\tau<1$ and a unit tax $T$ (in real terms $t=\frac{T}{w}$ ), firm $i$ 's profit is

$$
\pi_{i}=(1-\tau) P\left(x_{i}\right) x_{i}-\left(f+(\beta+t) x_{i}\right) w .
$$

Denoting by $c_{i}$ consumption of good $i$ and by $L$ the labour force assumed to be equal to the number of consumers, market clearing implies $x_{i}=L c_{i}$.

The model is completed by imposing a simple two-sector Dixit-Stiglitz utility function. Utility stems from the consumption of an un-taxed homogeneous good (say labour), and the consumption of differentiated goods from the taxed sector described above. In particular, utility identical for all individuals is assumed to be

$$
U=\left(\frac{\hat{l}}{L}\right)^{1-\alpha}\left(\sum_{i=1}^{n} c_{i}^{\theta}\right)^{\alpha}
$$

where $0<\theta<1$ and $\frac{\hat{l}}{L}$ is the per capita consumption of the homogeneous good at price $w$. Labour market clearing requires $\sum l_{i}+\hat{l}=L$. In this specification the elasticity of substitution between goods from the two different sectors is 1 which is less than the elasticity of substitution between products from within each sector. Further, maximising (2) expenditure shares on homogeneous and differentiated products will be $(1-\alpha)$ and $\alpha$ respectively. Market clearing requires $w L+R=w \hat{l}+\sum p_{i} x_{i}$, where $R$ are redistributed tax receipts. Further denote by $s$ the total expenditure on the homogeneous good, than we have $s=w \hat{l}=(1-\alpha)(w L+R)$, i.e. consumption of the homogeneous good is affected by taxation in the differentiated goods sector via redistributed revenue.

The inverse demand function for the taxed sector is calculated by maximising utility from the consumption of differentiated goods

\footnotetext{
${ }^{4}$ This section presents a straightforward application of Dixit and Stiglitz (1977) to public finance, much in the spirit of Atkinson and Stiglitz (1980, ch.7).
} 
$\left(\max \left(\sum c_{i}^{\theta}\right)^{\alpha}-\lambda\left(p_{1} c_{1}+\cdots+p_{i} c_{i}+\cdots+p_{n} c_{n}-\alpha(w+R)\right)\right.$. Given the large number of firms assumption, firms do not realise the impact of their price on overall sales (and on tax revenue). The first order conditions are of the form

$$
P\left(x_{i}\right)=\frac{\theta c_{i}^{\theta-1}}{\lambda \xi}
$$

where $\xi=\alpha\left(\sum c_{i}^{\theta}\right)^{1-\alpha}$ assumed to be constant and where $c_{i}=\frac{x_{i}}{L}$ (from the market clearing condition). Calculating the price elasticity of demand in absolute terms yields $\epsilon=\frac{1}{1-\theta}$.

Equilibrium in the taxed sector is characterised by prices, per firm output and the number of firms. Due to symmetry we can restrict our analysis to one variant (firm), hence, omitting the subscript $i$. Setting (3) into (1) and maximising yields the profit-maximising price

$$
p=\frac{(\beta+t) w}{(1-\tau) \theta}, .
$$

Equating the profit-maximising price with the price implied by zero profits, $p_{0}=\frac{(f+(\beta+t) x) w}{(1-\tau) x}$ gives the per firm output under free entry and exit:

$$
x=\frac{\theta f}{(1-\theta)(\beta+t)} .
$$

Finally, the number of firms actually producing in equilibrium can be deduced via market clearing using the $x$ and $p$ just derived. In particular, $p x n=$ $\alpha(w L+R)$ must hold. Expressing $R$ in real terms as $r=\frac{R}{w}$ gives

$$
n=\frac{\alpha(L+r)(1-\theta)(1-\tau)}{f} .
$$

Thus, while the ad valorem tax affects the number of firms, the unit tax affects output per firm. Further, only the number of firms reacts to redistributed tax revenues. Notice also from (4) that the unit tax is overshifted with factor $\frac{1}{\theta}$.

\section{Tax revenue and the resulting number of firms}

The total tax revenue, assuming that taxes are completely redistributed to consumers in a lump-sum fashion, is given by $\Gamma=\tau p x n+T x n$, where $n$ is given in (6) when $r=\frac{\Gamma}{w} .{ }^{5}$ Then expressing $\Gamma$ in real terms as $\gamma=\frac{\Gamma}{w}$, total

\footnotetext{
${ }^{5}$ All results extend readily to any level (including zero) of redistribution.
} 
tax revenue becomes

$$
\gamma=L \alpha\left(\frac{(\beta+t) \tau+(1-\tau) \theta t}{(\beta+t)(1-\tau \alpha)-t \theta \alpha(1-\tau)}\right) .
$$

The actual number of firms is calculated by setting $r=\gamma$ back into (6). Denoting by $n^{\tau}$ the case of an ad valorem tax $(t=0)$ and by $n^{t}$ the case of a unit $\operatorname{tax}(\tau=0)$ gives

$$
\begin{aligned}
n^{\tau} & =\frac{\alpha}{f}(1-\theta) L \frac{1-\tau}{1-\tau \alpha}, \\
n^{t} & =\frac{\alpha}{f}(1-\theta) L \frac{\beta+t}{\beta+t-t \theta \alpha} .
\end{aligned}
$$

Finally, from (7) the equal yield tax levels can be derived. Define a certain tax yield $\bar{\gamma}$. Given that the respective other tax is zero, the following ad valorem and unit tax levels result in $\bar{\gamma}$ :

$$
\begin{aligned}
\tau_{\bar{\gamma}} & =\frac{\bar{\gamma}}{\alpha(L+\bar{\gamma})}, \\
t_{\bar{\gamma}} & =\frac{\bar{\gamma} \beta}{\alpha \theta(L+\bar{\gamma})-\bar{\gamma}} .
\end{aligned}
$$

Since the ad valorem tax has to be strictly less than 1 , there exists an upper limit to the tax yield, in particular, setting $\tau=1$ in (10) gives $\bar{\gamma}^{*}=\frac{\alpha}{1-\alpha} L$.

\section{Results}

The tax rates defined in (10) and (11) have to be set into the per firm production level (5) and the respective number of firms derived in (8) and (9). Further, the expenditure share $s$ on the homogeneous good becomes now $s=(1-\alpha)\left(w L+\left.R\right|_{\tau=\tau_{\bar{\gamma}}}\right)=(1-\alpha)\left(w L+\left.R\right|_{t=t_{\bar{\gamma}}}\right)=(1-\alpha) w(L+\bar{\gamma})$. With these ingredients and utility function (2) the utility levels under the two different tax tools can be calculated (see appendix A.1). The utility difference, $\Delta_{\bar{\gamma}}=\left.U\right|_{\tau=\tau_{\bar{\gamma}}}-\left.U\right|_{t=t_{\bar{\gamma}}}$, between the two tax tools is:

$$
\begin{aligned}
\Delta_{\bar{\gamma}}= & \left((1-\alpha) \frac{L+\bar{\gamma}}{L}\right)^{1-\alpha}\left(\left(\frac{1-\theta}{f}(L \alpha-\bar{\gamma}(1-\alpha))\left(\frac{f \theta}{L \beta(1-\theta)}\right)^{\theta}\right)^{\alpha}\right. \\
& \left.-\left(\frac{1-\theta}{f} \alpha(L+\bar{\gamma})\left(\frac{f((L+\bar{\gamma}) \alpha \theta-\bar{\gamma})}{L(L+\bar{\gamma}) \alpha \beta(1-\theta)}\right)^{\theta}\right)^{\alpha}\right)
\end{aligned}
$$


Due to entry, profits are zero and all tax revenue is redistributed to the population, hence $\Delta_{\bar{\gamma}}$ is a measure of welfare. From (12) the following result is derived.

Proposition 1. Given a certain tax level $\bar{\gamma}$, an ad valorem tax, $\tau_{\bar{\gamma}}$, is welfare superior to the equal yield unit tax, $t_{\bar{\gamma}}$. In particular, $\Delta_{\bar{\gamma}}>0 \forall \bar{\gamma}<\bar{\gamma}^{*}, \bar{\gamma} \neq 0$.

Proof is given in appendix A.2. Proposition 1 establishes, that if some tax revenue is to be raised from a monopolistically competitive industry, an ad valorem tax is the preferable measure. Thus the welfare superior performance of ad valorem tax tools that has been established for a wide class of imperfect competition settings (e.g. Suits and Musgrave (1953) and Delipalla and Keen (1992)) does extend to a Dixit-Stiglitz-type framework of monopolistic competition.

This result is obtained, even though ad valorem taxation features fewer firms than an equivalent unit taxation. While this distortion skews the model towards a welfare dominance of unit taxes (love of variety), the lower efficiency of the unit tax (due to the greater over-shift) more than eats up this advantage, leaving the ad valorem tax as the superior tool. To see this, consider that total sector output is higher under the ad valorem tax than under the unit tax, i.e. $n^{\tau} x^{\tau}>n^{t} x^{t}$ for $\tau=\tau_{\bar{\gamma}}, t=t_{\bar{\gamma}}$. Furthermore, consider that the superiority of the ad valorem tax would be challenged if the policy objective is not a certain tax yield, $\bar{\gamma}$, but a certain corrective production volume $\overline{n x}$. Now the ability of the unit tax to induce a larger number of firms, each producing less output, can dominate the ad valorem tax. Finally, proposition 1 also applies to $\bar{\gamma}<0$, which means that if a subsidy - financed by a lump sum tax on income - is to be given to the differentiated goods sector, then an ad valorem subsidy is preferable to a per unit subsidy.

The result of proposition 1 presents a contrast to Anderson et al. (2001b, proposition 5). They found that in a setting with Bertrand competition, differentiated products, entry and love of variety, the dominance of ad valorem tax tools can be challenged by unit taxes. ${ }^{6}$ The present Dixit-Stiglitz-type monopolistic competition model has crucial features in common with Anderson et al. (2001b, proposition 5) - apart from the mode of competition - but does establish that ad valorem taxes are welfare superior. ${ }^{7}$ This hints at a

\footnotetext{
${ }^{6}$ In fact, Anderson et al. (2001a and 2001b) main contributions include to show that without love of variety most results concerning firm profits, consumer surplus, tax efficiency and the welfare ranking of the two tax instruments do compare well with the Cournot competition case presented by for example Delipalla and Keen (1992).

${ }^{7}$ Notice that while this paper uses the Dixit-Stiglitz approach towards love of variety,
} 
non-trivial impact from the mode of competition on the welfare ranking of ad valorem and unit tax instruments.

\section{Conclusion}

The present paper shows that the welfare-superiority of ad valorem taxes to equal yield unit taxes, that has been established for a wide range of imperfect competition settings (e.g. Suits and Musgrave (1953) and Delipalla and Keen (1992)), also applies to the case of Dixit-Stiglitz-type monopolistic competition, i.e. a setting which, like the majority of the literature on the subject to date, features Cournot type competition. This result presents a contrast to recent findings by Anderson et al. (2001b) in a setting with similar features - entry, differentiated products, love of variety - but with Bertrand competition.

The question of how the mode of competition affects the efficiency of tax instruments will be of continuing interest for future research. Further issues that should be examined for the monopolistic competition case presented here are the optimal combination of tax instruments and the welfare ranking of ad valorem and unit taxes for objectives other than a revenue target. Finally, the results of this paper carry implications for the use of ad valorem and unit tax (tariff) instruments in environmental and international economics.

i.e. directly utilising the convexity of the indifference surfaces of any well behaved utility function across potential commodities, Anderson et al. (2001b) rely on a discrete choice framework for consumer demand. Also, the result in proposition 1 - in contrast to Anderson et al. (2001b, proposition 5) - is independent of the taste for variety, $\theta$, the size of the fixed costs of production, $f$, the consumer preference for the differentiated goods sector, $\alpha$, and the size of the revenue requirement, $\bar{\gamma}$. 


\section{A Appendix}

\section{A.1 Utility expressions}

Ad Valorem tax: The tax rate $\tau_{\bar{\gamma}}$ given in (10) is plugged into the number of firms expression derived in (8). The per firm output volume is as given in (5) when $t=0$. Utilising market clearing, the fact that $c=\frac{x}{L}$, and that $s=(1-\alpha)\left(w L+\left.R\right|_{\tau=\tau_{\bar{\gamma}}}\right)=(1-\alpha) w(L+\bar{\gamma})$, these values are set into utility function (2):

$$
\left.U_{\tau_{\bar{\gamma}}}=\left((1-\alpha) \frac{L+\bar{\gamma}}{L}\right)^{1-\alpha}\left(\frac{1-\theta}{f}(\alpha(L+\bar{\gamma})-\bar{\gamma})\right)\left(\frac{f \theta}{L(1-\theta) \beta}\right)^{\theta}\right)^{\alpha} .
$$

Unit tax: The tax rate $t_{\bar{\gamma}}$ given in (11) is plugged into the number of firms expression derived in (9) and the per firm output volume in (5). Utilising market clearing, the fact that $c=\frac{x}{L}$, and that $s=(1-\alpha)\left(w L+\left.R\right|_{t=t_{\bar{\gamma}}}\right)=$ $(1-\alpha) w(L+\bar{\gamma})$, these values are set into utility function $(2)$ :

$U_{t_{\bar{\gamma}}}=\left((1-\alpha) \frac{L+\bar{\gamma}}{L}\right)^{1-\alpha}\left(\frac{1-\theta}{f} \alpha(L+\bar{\gamma})\left(\frac{f \theta}{L(1-\theta)\left(\beta+\frac{\beta \bar{\gamma}}{(L+\bar{\gamma}) \alpha \theta-\bar{\gamma}}\right)}\right)^{\theta}\right)^{\alpha}$

Expression (A.1 ) and (A.2) show the utility portion stemming from the consumption of the homogeneous and differentiated goods respectively. The fact that $n^{\tau_{\bar{\gamma}}}<n^{t_{\bar{\gamma}}}$ and $x^{\tau_{\bar{\gamma}}}>x^{t_{\bar{\gamma}}}$ is verified by inspection.

\section{A.2 Proof of Proposition 1}

Proof. $\Delta_{\bar{\gamma}}>0 \forall \bar{\gamma}<\bar{\gamma}^{*}, \bar{\gamma} \neq 0$.

The expression for $\Delta_{\bar{\gamma}}$ in (12) is

$$
\Delta_{\bar{\gamma}}=(a)^{1-\alpha}\left((b)^{\alpha}-(d)^{\alpha}\right)
$$

where $a=(1-\alpha) \frac{L+\bar{\gamma}}{L}, \quad b=\frac{1-\theta}{f}(L \alpha-\bar{\gamma}(1-\alpha))\left(\frac{f \theta}{L \beta(1-\theta)}\right)^{\theta}$ and $d=$ $\frac{1-\theta}{f} \alpha(L+\bar{\gamma})\left(\frac{f((L+\bar{\gamma}) \alpha \theta-\bar{\gamma})}{L(L+\bar{\gamma}) \alpha \beta(1-\theta)}\right)^{\theta}$. Since $a>0$, one has to show that $b>d$. This inequality can be rewritten as

$$
\frac{\alpha(L+\bar{\gamma})-\bar{\gamma}}{\alpha(L+\bar{\gamma})}>\left(\frac{\theta \alpha(L+\bar{\gamma})-\bar{\gamma}}{\theta \alpha(L+\bar{\gamma})}\right)^{\theta}
$$

Define the function

$$
q(k)=\left(\frac{k \alpha(L+\bar{\gamma})-\bar{\gamma}}{k \alpha(L+\bar{\gamma})}\right)^{k}
$$


If $q(k)$ is monotone increasing in $k$, then $1>\theta \Leftrightarrow b>d$ and thus (A.4) and $\Delta_{\bar{\gamma}}>0$ holds.

Monotonicity of $q(k)$ : Differentiating (A.5) with respect to $k$ gives

$$
\frac{d q(k)}{d k}=\frac{(e)^{k} g}{h}
$$

where $e=1-\frac{\bar{\gamma}}{k(L+\bar{\gamma}) \alpha}, h=k(L+\bar{\gamma}) \alpha-\bar{\gamma}$ and $g=\bar{\gamma}+h \ln (e)$. Since $\bar{\gamma}<\frac{\alpha}{1-\alpha} L=\bar{\gamma}^{*}$ must be fulfilled, $e, h>0$ holds. Hence it remains to be shown that $g=\bar{\gamma}+(k(L+\bar{\gamma}) \alpha-\bar{\gamma}) \ln \left(1-\frac{\bar{\gamma}}{k(L+\bar{\gamma}) \alpha}\right)>0$. Rewriting yields

$$
\frac{k \alpha(L+\bar{\gamma})}{k \alpha(L+\bar{\gamma})-\bar{\gamma}}-1>\ln \left(\frac{k \alpha(L+\bar{\gamma})}{k \alpha(L+\bar{\gamma})-\bar{\gamma}}\right)
$$

which is always true. 


\section{References}

Anderson, Simon P.; de Palma, André; Kreider, Brent (2001a), Tax Incidence in Differentiated Product Oligopoly, Journal of Public Economics, Vol. 81, pp. 173-192.

Anderson, Simon P.; de Palma, André; Kreider, Brent (2001b), The Efficiency of Indirect Taxes under Imperfect Competition, Journal of Public Economics, Vol. 81, pp. 231-251.

Atkinson, Anthony B.; Stiglitz, Joseph E. (1980), Lectures on Public Economics, McGraw-Hill.

Delipalla, Sofia; Keen, Michael (1992), The Comparison between Ad Valorem and Specific Taxation under Imperfect Competition, Journal of Public Economics

Dixit, Avinash K.; Stiglitz, Joseph E. (1977), Monopolistic Competition and Optimum Product Diversity, American Economic Review, Vol. 67(3), pp. 297-308.

Hamilton, Stephen F. (1999), Tax Incidence under Oligopoly: A Comparison of Policy Approaches, Journal of Public Economics, Vol. 71, pp. 233-245.

Keen, Michael (1998), The Balance between Specific and Ad Valorem Taxation, Fiscal Studies, Vol. 19, pp.1-37.

Myles, Gareth D. (1996), Imperfect Competition and the Optimal Combination of Ad Valorem and Specific Taxation, International Tax and Public Finance, Vol. 3, pp. 29-44.

Skeath, Susan E.; Trandel, Gregory A. (1994), A Pareto Comparison of Ad Valorem and Unit Taxes in Noncompetitive Environments, Journal of Public Economics, Vol. 53, pp. 53-71.

Stern, Nicholas (1987), The Effects of Taxation, Price Control and Government Contracts in Oligopoly and Monopolistic Competition, Journal of Public Economics, Vol.32, pp. 133-158.

Suits, D.B.; Musgrave, R.A. (1953), Ad Valorem and Unit Taxes Compared, Quarterly Journal of Economics, Vol. 67, pp.598-604. 